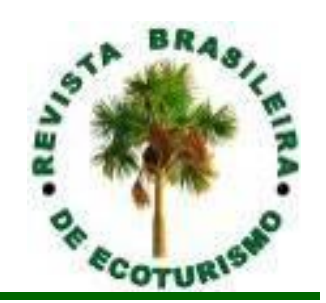

\title{
Turismo Pedagógico para Educação Ambiental durante o lazer no Parque das Dunas em Natal (RN)
}

\section{Pedagogical Tourism for Environmental Education during the leisure in the Dunas Park in Natal (RN, Brazil)}

Aretha Julianna Moura-dos-Santos, Mauro Lemuel Oliveira-Alexandre, Ana Beatriz Gomes-Ferreira, Juliana Garcia Vidal-Rodrigues, Sueli Aparecida Moreira

\begin{abstract}
RESUMO: O parque urbano representa importante papel na qualidade de vida da população local e pode contribuir na percepção ambiental durante a prática do lazer. Com objetivo de avaliar o potencial do parque para Educação Ambiental durante o lazer, realizou-se pesquisa qualitativa cujos dados foram obtidos por meio de analise documental e depoimento obtido com a gestão do parque. O parque constitui espaço adequado para promover a educação/sensibilização ambiental (ao revelar a fauna, a flora e espécies endêmicas) para escolares em turismo pedagógico. As ações ambientais alinham-se sob a ética do desenvolvimento sustentável. O Parque constitui uma alternativa para o ecoturismo para visitantes e turistas em Natal.
\end{abstract}

PALAVRAS CHAVE: Educação Ambiental; Turismo Sustentável; Turismo e Ecologia; Mata Atlântica Setentrional.

ABSTRACT: The urban park represents an important role in the quality of life of the local population and can contribute to environmental perception during leisure practice. In order to evaluate the potential of the park for environmental education during leisure time, a qualitative research was conducted, whose data were obtained through documental analysis and testimony obtained with the park management team. The park constitutes an adequate space to promote education/environmental awareness (by revealing the fauna, flora and endemic species) for schoolchildren in pedagogical tourism. Environmental actions align under the ethics of sustainable development. The park is an alternative to ecotourism for visitors and tourists in Natal.

KEYWORDS: Environmental Education; Sustainable Tourism; Tourism and Ecology; Northern Atlantic Forest. 


\section{Introdução}

O Parque Estadual Dunas do Natal, Jornalista Luiz Maria Alves, conhecido como Bosque dos Namorados ou simplesmente Parque das Dunas, localiza-se em uma Unidade de Conservação dentro do perímetro urbano do município de Natal, Estado do Rio Grande do Norte, com uma área de 1.172 hectares de Mata Atlântica, com oferta de diversas atividades ao ar livre.

O fato de favorecer o lazer em contato com a natureza faz das Unidades de Conservação a matéria-prima para o ecoturismo. Face à busca crescente pelo turismo ecológico, o Parque das Dunas na cidade de Natal representa um importante atrativo, pois trata-se de um dos maiores parques de mata atlântica do país. A mata atlântica está em primeiro lugar entre os hotspots mundiais de biodiversidade e abriga mais de 8.000 espécies endêmicas de plantas e animais, totalizando em média de $2 \%$ da totalidade das espécies mundiais; e que a cada ano, vem recebendo uma quantidade significativa de turistas, além de visitantes locais, mas também de outras regiões do Brasil, além de turistas estrangeiros (MYERS et. al. 2000).

As Unidades de Conservação (UCs) são espaços territoriais com características naturais relevantes, legalmente instituídos pelo Poder Público, com objetivos de conservação e limites definidos, sob regime especial de administração, ao qual se aplicam garantias adequadas de proteção (Lei 9.985/2000). Podem ser instituídas pelo poder público (federal, estadual e municipal) ou voluntariamente por iniciativa privada, e estão organizadas sobre a forma de um sistema - o Sistema Nacional de Unidade de Conservação (SNUC). As UCs recobrem significativa parcela do território nacional, protegendo ecossistemas, espécies e meios de vida de populações tradicionais que garantem a provisão de diversos serviços ecossistêmicos essenciais para o bem-estar da humanidade. Somente na esfera federal são 333 Unidades de Conservação que correspondem a 9\% do território continental e 24\% do território marinho (YOUNG; MEDEIROS, 2018).

Enquanto vale o verde, constatou-se que a proteção das UCs contribui significativamente para a economia nacional através de bens e serviços. Entre 2006 a 2016, os rendimentos compensaram os investimentos com o SNUC, pela obtenção de produtos florestais, através do uso público das áreas protegidas, o estoque de carbono, a produção de água, proteção dos solos e a geração de receita tributária para municípios. Destaca-se, ainda, sua importância para combater e reduzir os efeitos causados pelas mudanças climáticas globais bem como para promover o desenvolvimento sustentável (YOUNG; MEDEIROS, 2018)

Com base em dados de visitação consistentes, o planejamento e ordenamento do turismo em parques e outras unidades de conservação tendem a promover uma maior visitação e incrementar os impactos econômicos do uso público, sem comprometer a conservação dos ecossistemas, atendendo assim aos seguintes objetivos do SNUC: conservar a biodiversidade e proporcionar experiências em contato com a natureza (YOUNG; MEDEIROS, 2018).

Turismo em áreas naturais protegidas consta do Plano Nacional de Turismo para contribuir financeiramente com as Unidades de Conservação (UC) e melhorar a promoção do desenvolvimento sustentável, gerando emprego e renda nos municípios de inserção dos Parques;

Faz parte da Agenda Estratégica de Políticas Públicas em Turismo no Brasil a 
ser alcançada até 2022: Consolidar o ecoturismo e o turismo sustentável como estratégias de conservação e preservação da natureza, elevando a qualidade dos serviços turísticos ofertados, assim como a qualificação e o profissionalismo do turismo nas áreas protegidas e seu entorno; Definir uma estratégia geral de valorização do espaço protegido brasileiro, como fator de desenvolvimento regional, a partir de um turismo qualificado (Mtur, 2012).

A Educação Ambiental desempenha importante papel através de ações capazes de sensibilizar para os problemas planetários, o esgotamento de recursos naturais, valores éticos como cooperação e respeito à diversidade (CARVALHO, 2006). Para empreender o turismo de forma sustentável convém instrumentalizar a Educação Ambiental desde o planejamento turístico, integrando ações que estimulem a percepção ambiental e revelem a biodiversidade; demonstrem o uso racional de recursos e valorizem a identidade cultural local.

O planejamento turístico estratégico do Parque requer identificar o perfil do turista que atende; caracterizar as práticas de lazer e verificar as potencialidades para o turismo ecológico; infraestrutura adequada e estratégias de divulgação no leque de atrativos turísticos. Portanto, o presente estudo tem como objetivo caracterizar o potencial da atividade turística em Educação Ambiental durante o lazer do Parque das Dunas.

\section{Método}

A pesquisa é de natureza qualitativa e envolveu a obtenção de depoimento de dois gestores do parque. Os depoentes foram considerados atores sociais aptos a promover a sensibilização ambiental durante o lazer no contexto urbano.

Para obter o depoimento da gestão, utilizou-se de roteiro guia aplicado em 2016, em local privativo do Parque das Dunas. O roteiro contemplava questões sobre turismo pedagógico e Educação Ambiental durante o lazer. Posteriormente, realizou-se análise de conteúdo conforme Bardin (1977) para inferência e interpretação dos depoimentos. Realizou-se, ainda, a análise de documentos contendo informações sobre o perfil do Parque para o turismo ecológico.

\section{Caracterização da área de estudo}

O potencial do Parque como atrativo turístico é imenso, pois trata-se de uma Unidade de Conservação de Proteção Integral (SNUC, Lei Federa no 9.985/2000), cujo planejamento se dedica a consolidar a proteção de seus recursos naturais, ampliando as ações de Educação Ambiental e consolidando as práticas nas áreas de uso público e de uso semi-intensivo.

A caracterização do parque foi elaborada a partir de depoimentos da equipe de gestores e com base na análise de documentos fornecidos pelos mesmos:

\footnotetext{
"O Parque das Dunas é uma área de importância vital para a cidade do Natal. Foi a primeira unidade de conservação do Estado do Rio Grande do Norte, abrangendo uma área de 1.172 hectares do Bioma Mata Atlântica, contribuindo com serviços ambientais sendo eles: climatização da cidade, abastecimento de uma parte da cidade com a água. Área de grande biodiversidade entre fauna e flora, entre outros" (Depoimento da Gestão, 2016).
} 


\begin{abstract}
"O Parque das Dunas foi concebido com a premissa de contemplar a preservação e a conservação dos serviços ambientais prestados por seus ecossistemas naturais; proteção de recursos genéticos da fauna e da flora nativas, resguardando sua biodiversidade; a realização de estudos, pesquisas, trabalhos de interesse científico e de monitoramento; preservação de sítios de valor histórico, arqueológico e geomorfológico e oferecer condições para lazer, turismo ecológico e realização de atividades educativas e de conscientização ecológica" (análise documental).
\end{abstract}

O Parque das Dunas é gerido pelo IDEMA e recebe uma média anual de 150.000 visitantes, mantendo ainda um cadastro com cerca de 10.000 coopistas que praticam atividade física. O Parque também arrecada valores simbólicos com a venda de ingressos ao preço de um real por visitante. O ingresso funciona como ferramenta de controle da frequência de visitantes ao parque. Contudo, do ponto de vista estrutural "necessita de uma abordagem a respeito da manutenção e de suas condições de funcionamento" (Depoimento da Gestão, 2016).

Dentre os atrativos o Parque são mantidas atividades de Educação Ambiental como "trilhas interpretativas" e atividades de lazer no Bosque dos Namorados, área de Uso Público com exuberante arborização e energia revigorante. Também são oferecidos "eventos culturais como Bosque Cena, Som da Mata, Dançando nas Dunas" (Depoimento da Gestão, 2016).

"O perfil de usuários do Parque das Dunas é bastante diversificado, variando de crianças até idosos, da comunidade local, nacional e internacional' (Depoimento da Gestão, 2016).

A divulgação do Parque ocorre em português e inglês através "do site (www.parquedasdunas.rn.gov.br), bem como toda a programação e eventos com assessoria de imprensa do IDEMA" (Depoimento da Gestão, 2016). Embora o setor turístico seja parte de um sistema integrado, "não há uma relação formalizada ou estabelecida que integre o Parque ao leque de atrativos regionais" (Depoimento da Gestão, 2016).

A localização do Parque, ao lado do maior Shopping Center de Natal, favorece a acessibilidade devido à infraestrutura de transporte público. No entanto, do ponto de vista da conservação ambiental, a localização em área urbana recebe uma enorme pressão social que anseia pela ocupação da fração protegida.

Do ponto de vista de recursos humanos, o parque conta com apenas três servidores, graduados em biologia, que são vinculados diretamente ao parque. Os demais funcionários que cuidam das dependências do parque, são terceirizados; Boa parte das atividades de Educação Ambiental é desenvolvida por estagiários.

O Parque das Dunas vem obtendo reconhecimento e premiações. Em 1994 Reconhecimento oficial do Parque como parte da Reserva da Biosfera da Mata Atlântica Brasileira pela UNESCO; Em 1999 - Reconhecimento do Conselho Nacional da Reserva da Biosfera da Mata Atlântica - RBMA, como Posto Avançado da Mata Atlântica Brasileira e em 2013 foi considerado o (5ํ) quinto melhor parque do Brasil pela Tripadvisor. 


\section{Resultados e Discussão}

\section{Turismo e Meio Ambiente}

O turismo é uma atividade longínqua que data desde as antigas civilizações, contudo sua evolução ocorreu mais recentemente no final do século $X X$, gerando empregos, divisas e riquezas. O advento da Revolução Industrial e o surgimento das divisões do tempo (tempo biológico, o tempo do trabalho, o tempo do descanso e o tempo inoperante); o tempo livre somado às férias, o aumento de salário e grau de educação, motivaram necessidades de conhecer outras culturas, visto que, viajar era visto como um atributo de educação que configurava o turismo (RUSCHMANN, 2001). A revolução industrial e os inventos que dela advém forneceram grandes aparatos ao turismo, como a navegação a vapor, ferrovias e as inovações tecnológicas (BECKER, 2006). Contudo, a definição de turismo é complexa:

O turismo é o conjunto de todas as atividades sociais, culturais, políticas, econômicas e naturais que envolvem pessoas se deslocando pelos mais diversos lugares em busca de outros destinos desconhecidos ou não, com uma permanência temporária (BELTRÃO, 2001, p. 18).

O turismo inclui tanto o deslocamento e as atividades realizadas pelas pessoas durante suas viagens e estadas, bem como, as relações que surgem entre eles, em lugares distintos de seu ambiente natural, por um período de tempo consecutivo inferior a um ano e mínimo de $24 \mathrm{~h}$ (pernoite no destino), principalmente com fins de lazer, negócio e outros (OMT, 2016).

Em decorrência da industrialização e urbanização ocorreu uma redução de espaços ao ar livre destinados à prática de lazer. A falta de "área verde" e os impactos psicológicos da vida urbana demandam viagens de férias e o lazer de fim de semana (RUSCHMANN, 2001). Com o direito às férias turistas de países desenvolvidos encontraram facilidades na aquisição de pacotes turísticos de viagens, acessíveis e parceláveis. O turismo de massa trouxe sérios impactos ao meio ambiente de locais receptores, impactos na cultura, impactos sobre as paisagens, inclusive a própria propaganda de marketing do meio ambiente acaba atraindo seu verdadeiro público alvo, massificando o fluxo turístico no local receptor o que acaba por não ser o intuito do ecoturismo, que, não pode receber uma carga maior que sua capacidade, o comprometimento desses limites custam à sensibilidade do ecossistema (RUSCHMANN, 2001).

O ecoturismo surge no Brasil como forma de Educação Ambiental na década de 1980, com suas paisagens sendo buscadas como preferência nos destinos turísticos, sendo mais apreciadas e usadas como escape pelos turistas que se sentiam estagnados pelos roteiros comuns e convencionais "e estresse gerado nos grandes centros urbanos. A fuga da agitação cotidiana impulsionou as viagens às regiões naturais e a natureza passou a ser vista como um argumento comercial e valioso" sendo bastante desenvolvida e comercializada de forma que geram um fundamento econômico à conservação e preservação das áreas naturais para, que elas não se acabem e continuem sendo bons destinos por muito tempo do que acabar com os recursos e não se ter mais nada para visitar depois (SILVA \& SANTOS, 2010). 
O ecoturismo surge como uma forma de diminuir o turismo de massa utilizando os recursos da natureza, porém, de forma que não a degrade mais, uma "forma alternativa de fazer turismo, buscando a conservação, o entendimento e apreciação do meio ambiente e das culturas visitadas" (SILVA; SANTOS, 2010).

Ecoturismo compreende a atividade turística que utiliza, de forma sustentável, o patrimônio natural e cultural, incentiva sua conservação e busca a formação de uma consciência ambientalista através da interpretação do ambiente, promovendo o bem-estar das populações envolvidas (BARBOSA; ZAMBONI, 2000).

Ecoturismo ou Turismo Ecológico depende de políticas públicas de conservação e preservação do meio ambiente. Na legislação brasileira, meio ambiente está previsto na Lei oㅜ 6.938, de 31 de agosto de 1981, que trata da Política Nacional do Meio Ambiente, dispõe no artigo $3^{\circ}$, inciso I: "Para os fins previstos nesta Lei, entende-se Meio ambiente: "o conjunto de condições, leis, influências e interações de ordem física, química e biológica, que permite, abriga e rege a vida em todas as suas formas".

Em verdade, não há uma uniformidade doutrinária para a definição do meio ambiente, contudo meio ambiente em sentido amplo é gênero que inclui o meio ambiente natural, cultural, artificial, juntamente com o meio ambiente do trabalho conforme a Resolução CONAMA no 306/2002, anexos I e II. Contudo, Silva (1998) acrescenta o conceito de espaços ambientais:

Toda e qualquer delimitação geográfica, toda e qualquer porção do território nacional, estabelecida com o objetivo de proteção ambiental, integral ou não, e assim submetida a um regime especialmente protecionista (SILVA, 1998, p. 158.)

Unidades de conservação são espaços com características naturais relevantes, que têm a função de garantir a representatividade de amostras significativas e ecologicamente viáveis das diferentes populações, habitats e ecossistemas do território nacional e das águas jurisdicionais, preservando o patrimônio biológico existente. As Unidades de Conservação asseguram o uso sustentável dos recursos naturais e ainda propiciam às comunidades envolvidas 0 desenvolvimento de atividades econômicas sustentáveis em seu interior ou entorno (MINISTÉRIO DO MEIO AMBIENTE, 2016).

O Sistema Nacional de Unidades de Conservação (SNUC) é composto pelo conjunto de unidades de conservação federais, estaduais, municipais e particulares, distribuídas em doze categorias de manejo. Cada uma dessas categorias se diferencia quanto à forma de proteção e usos permitidos. Há unidades de proteção integral, que precisam de maiores cuidados por sua fragilidade e particularidades ambientais, e há unidades de uso sustentável, cujos recursos naturais podem ser utilizados de forma direta e sustentável conforme o Artigo 11 da Lei Federal 9.985/2000. A categoria parque, que é onde se insere o Parque das Dunas, é uma unidade de conservação de proteção integral. Assim, as unidades de conservação formam uma rede, na qual cada categoria contribui de uma forma específica para a conservação dos recursos naturais (SNUC, 2000). 


\section{Parque das Dunas, Unidade de Conservação}

Para que haja uma conservação da biodiversidade é necessário realizar condutas de proteção referentes à defesa da diversidade biológica. Como podem existir inúmeras áreas possíveis à proteção para recursos quase escassos, alguns requisitos são seguidos, como por exemplo, a verificação e identificação de espécies que indiquem características para uma intervenção prioritária, onde poderão ser investidos esses recursos voltados para essa biodiversidade (MANETTA et. al., 2001).

Essas áreas protegidas são as Unidades de Conservação (UCs), de acordo com o Sistema Nacional de Unidades de Conservação da Natureza (SNUC) há regras e especificações para "a criação, implantação e gestão das unidades de conservação" (BRASIL, 2000). A Lei № 9.985, de 18 de Julho de 2000, afirma que:

Unidade de conservação: espaço territorial e seus recursos ambientais, incluindo as águas jurisdicionais, com características naturais relevantes, legalmente instituído pelo Poder Público, com objetivos de conservação e limites definidos, sob regime especial de administração, ao qual se aplicam garantias adequadas de proteção (BRASIL, 2000).

O Parque das Dunas foi a primeira Unidade de Conservação do Rio Grande do Norte, criado em 22 de novembro de 1977, reconhecida pela Organização das Nações Unidas para a Educação, a Ciência e a Cultura (UNESCO) como: "parte integrante da Reserva da Biosfera da Mata Atlântica Brasileira e Bioma Mata Atlântica" (PARQUE DAS DUNAS, 2016).

O Parque das Dunas também é considerado o maior parque sobre dunas em todo território brasileiro. Foi à primeira Unidade de Conservação do Rio Grande do Norte estabelecido pelo Decreto Estadual o 7.237 de 1977 e veio a se solidificar como uma Unidade de Conservação em junho 1989, mesmo período em que recebeu seu Plano de Manejo (SEARH/COTIC, 1977). O Parque abrange uma área da Mata Atlântica, rica em seus recursos naturais, onde se organiza também, atividades turísticas, de lazer e ócio criativo juntamente a atividades de natureza educativa, científica e de conscientização ecológica (CARVALHO, 2001).

O Parque das Dunas é gerido pelo Instituto de Desenvolvimento Sustentável e Meio Ambiente (IDEMA). O IDEMA é uma autarquia fruto da união de atribuições entre a Fundação Instituto de Desenvolvimento do RN (IDEC), criada pela Lei n.. 4.286, de 06 de dezembro de 1973, (alterada pela Lei $n .0$ 4.414, de 04 de novembro de 1974), e a Coordenadoria de Meio Ambiente (CMA), criada por meio do Decreto n. 0.718 de 16 de setembro de 1983 (SECOM/IDEMA,1974).

No ano de 1995, por meio da Lei Complementar n. .0129 de 02 de fevereiro, a Fundação IDEC é vinculada à Secretaria de Estado do Planejamento e das Finanças (SEPLAN/RN) e, no ano seguinte, transformada em Instituto de Desenvolvimento Econômico e Meio Ambiente do Rio Grande do Norte (IDEMA) - através da Lei Complementar n. .0139 de 25 de janeiro. Nesse momento, o IDEMA incorpora as atribuições da então Coordenadoria de Meio Ambiente (CMA), também vinculada à SEPLAN/RN, e absorve a competência, dentre outras, de formular, coordenar, executar e supervisionar a política estadual de preservação, conservação, aproveitamento, uso racional e recuperação dos recursos ambientais, bem como 
fiscalizar o cumprimento das normas de proteção, controle, utilização e recuperação dos recursos ambientais, aplicando as penalidades disciplinares e/ou compensatórias às infrações apuradas.

No dia 31 de janeiro de 2007, a Lei Complementar n. 340 transformava o IDEMA em Instituto de Defesa do Meio Ambiente, sem que esse mudasse sua sigla. No ano seguinte, por meio da Lei Complementar n. 0380 de 27 de dezembro de 2008, o órgão ambiental vinculou-se à Secretaria de Estado do Meio Ambiente e dos Recursos Hídricos (SEMARH/RN), passando a chamar-se Instituto de Desenvolvimento Sustentável e Meio Ambiente. Então, o IDEMA adquiriu caráter ambiental, retroagindo sua data de fundação para 16 de setembro de 1983 (SECOM/IDEMA, 2016).

O IDEMA tem como atribuições a Promoção de Educação Ambiental, Licenciamento e Revisão de Atividades Potencialmente Poluidoras, Zoneamento Ambiental, Aplicação de Penalidades Disciplinares e Compensatórias, Implantação de Unidades de Conservação, Controle Ambiental e Controle Florestal (IDEMA, 2016).

A atuação do IDEMA em Natal é complexa, pois o município concentra um considerável número de Áreas de Preservação Ambiental (APAs) ou Zonas de Proteção Ambiental (ZPA), com abrangência de, aproximadamente, $40 \%$ do território urbano. O Plano Diretor do Município de Natal/RN obteve uma lei complementar para salvaguardar as zonas de proteção ambiental em (2007) referente às (ZPA's) Zonas de Proteção Ambiental (Lei complementar no 082/2007). Então, o novo plano diretor registra 10 zonas de proteção ambiental, sendo que somente 5 encontram-se regulamentadas e, notavelmente, são aquelas responsáveis pelo abastecimento do aquífero urbano. O Parque Estadual das Dunas de Natal concentra-se na ZPA 2 (Figura 1).

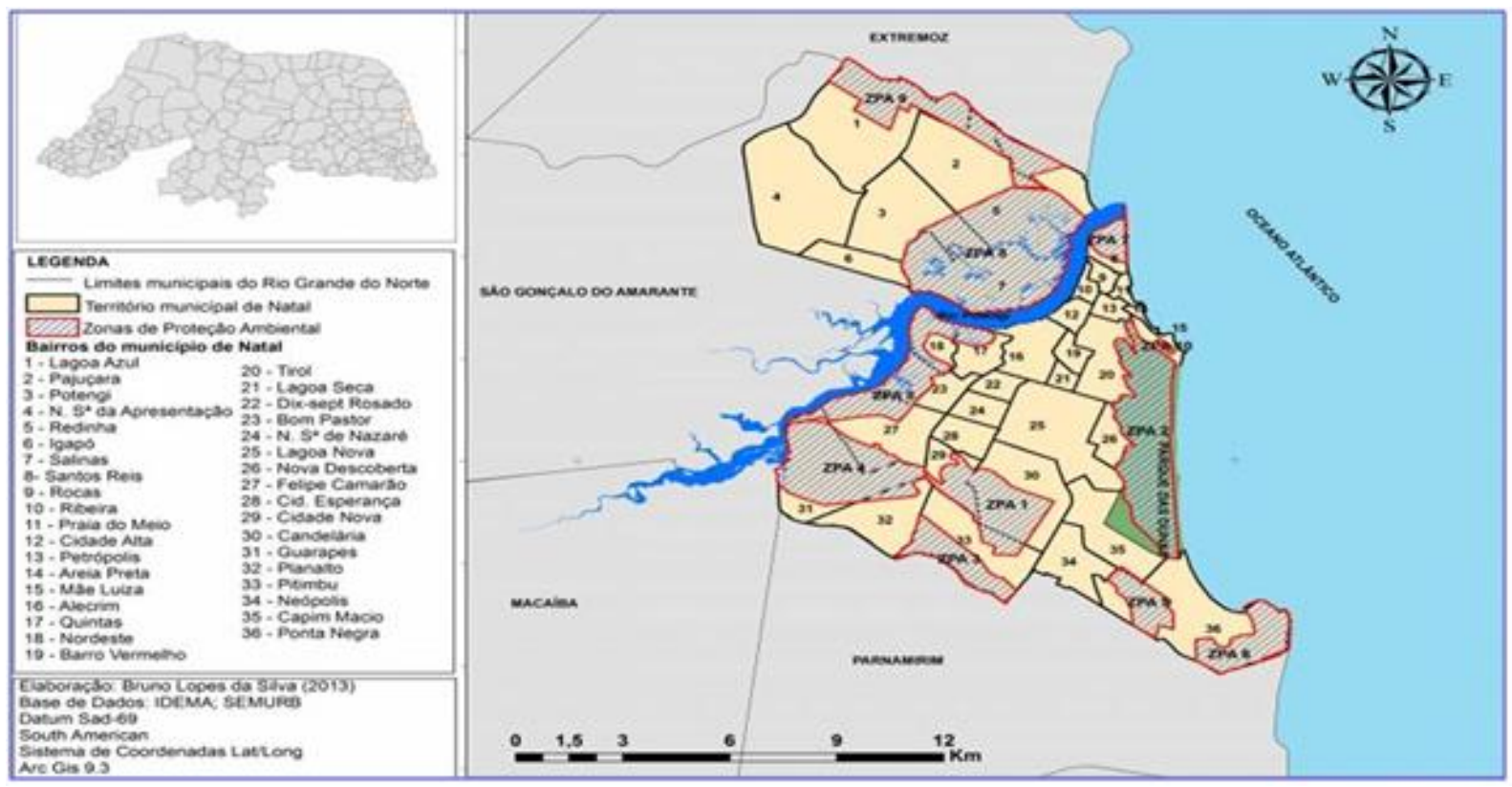

Figura 1: Zonas de Proteção Ambiental de Natal, 2007 Fonte: IDEMA, 2012.

Figure 1: Environmental Protection Areas of Natal, 2007. Source: IDEMA, 2012.

A Lei Complementar (no 082/2007) do Plano Diretor do Município de Natal/RN subdivide as 10 ZPA's em três subzonas: Subzona de preservação, subzona de 
conservação onde concentra-se as Zonas Especiais de Interesses Turísticos (ZET's). O Parque das Dunas contempla três atributos categorizados na subzona de preservação que compete preservar: Dunas, a vegetação fixadora de dunas, a vegetação de mangue, os recifes e as falésias, nos termos do art. $3^{\circ}$ do Código Florestal; A cobertura vegetal que contribua para a estabilidade das encostas sujeitas à erosão e deslizamentos e demais áreas nos termos do art. $3^{\circ}$ do Código Florestal; As áreas que abriguem exemplares raros, ameaçados de extinção ou insuficientemente conhecidos, da flora e da fauna, bem como aquelas que sirvam como local de pouso, abrigo ou reprodução de espécies.

\section{Patrimônio Natural do Parque}

O Parque das Dunas tem por objetivo garantir a preservação e conservação dos ecossistemas naturais englobados; proteger os recursos genéticos; possibilitar a realização de estudos, pesquisas e trabalhos de interesse científico; preservar sítios de valor histórico, arqueológico e geomorfológico; além de oferecer condições para o lazer, o ecoturismo e a realização de atividades educativas e de conscientização ecológica, Lei Federal 9.985/200 (SNUC, 2016).

A cobertura vegetal do Parque das Dunas é representada, em sua maior parte, pela mata de duna litorânea, caracterizada por espécies herbáceas, arbustivas e arbóreas, registrando ainda a ocorrência de praias e sopés de dunas, e formação vegetal tabuleiro litorâneo. Nela predominam espécies peculiares da mata atlântica, além de algumas espécies da caatinga e tabuleiro, com destaque para a amescla-de-cheiro, antúrio selvagem e pau-brasil, as quais conferem ao ambiente grande diversidade e exuberância. A flora reúne mais de 270 espécies arbóreas distintas e 78 famílias, representada por mais de 350 espécies endêmicas (Figura 2).
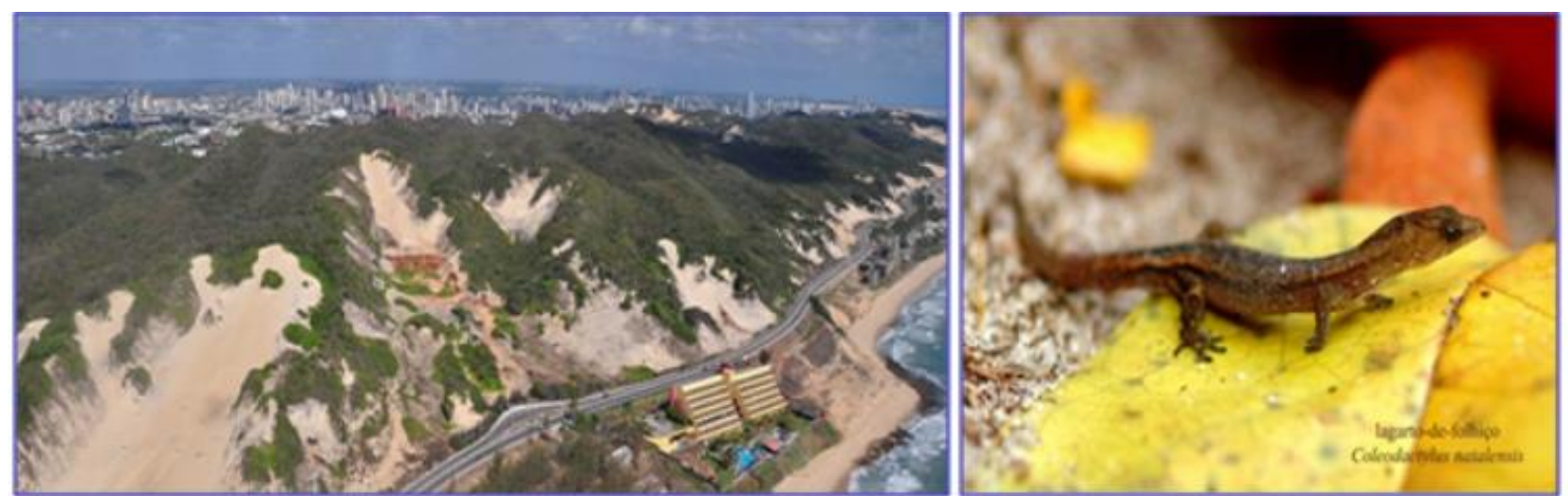

Figura 2: A) Ecossistema Dunar. Parque das Dunas, Natal/2017; B) Coleodactylus natalensis. Parque das Dunas/Natal, 2006. Fonte: A) Governo do RN, 2017/ B)Parque das Dunas, 2006. Figure 2: A) Dunes Ecosystem. Dunas Park, Natal/2017; B) Coleodactylus natalensis, Dunas Park/ Natal, 2006. Source: A)Government of the RN,2017.B)Dunas Park, 2006.

A fauna nativa do Parque é típica do ecossistema costeiro terrestre formado pela Mata Atlântica. De acordo com levantamento preliminar, a fauna do Parque está representada por cerca de 180 espécies dentre mamíferos, répteis, aves, e invertebrados, como borboletas, aranhas e escorpiões. O coleodactylus natalensis, o lagartinho-de-folhiço é uma das espécies endêmicas ameaçadas de extinção, tem sido utilizado como atrativo turístico e emblema para conservação do Parque das Dunas. 


\section{Turismo e Lazer no Bosque dos Namorados}

A fração de uso púbico do Parque corresponde ao Bosque dos Namorados (Figura 3). O Bosque dos Namorados ocupa aproximadamente uma área de 7 hectares, com uma faixa média de mil e trezentas árvores nativas do bioma Mata Atlântica. É também, nessa parte do Parque, onde se localizam os seus principais setores, a sede administrativa do Parque das Dunas se localiza na área do Bosque dos Namorados. O Bosque concentra diversas alternativas de lazer como:

Centro de Visitantes; Unidade Mostra de Vegetação Nativa; Centro de Pesquisa, com laboratórios de botânica e zoologia; Anfiteatro Pau-Brasil; Folha das Artes; Setor de Informações; Oficina de Educação Ambiental e Artes; Viveiro de Mudas; Área de Piquenique; tabuleiro de xadrez gigante (solicitar as peças na administração); Restaurante; Área de Descanso e a Área do Parque Infantil (PARQUE DAS DUNAS, 2016).
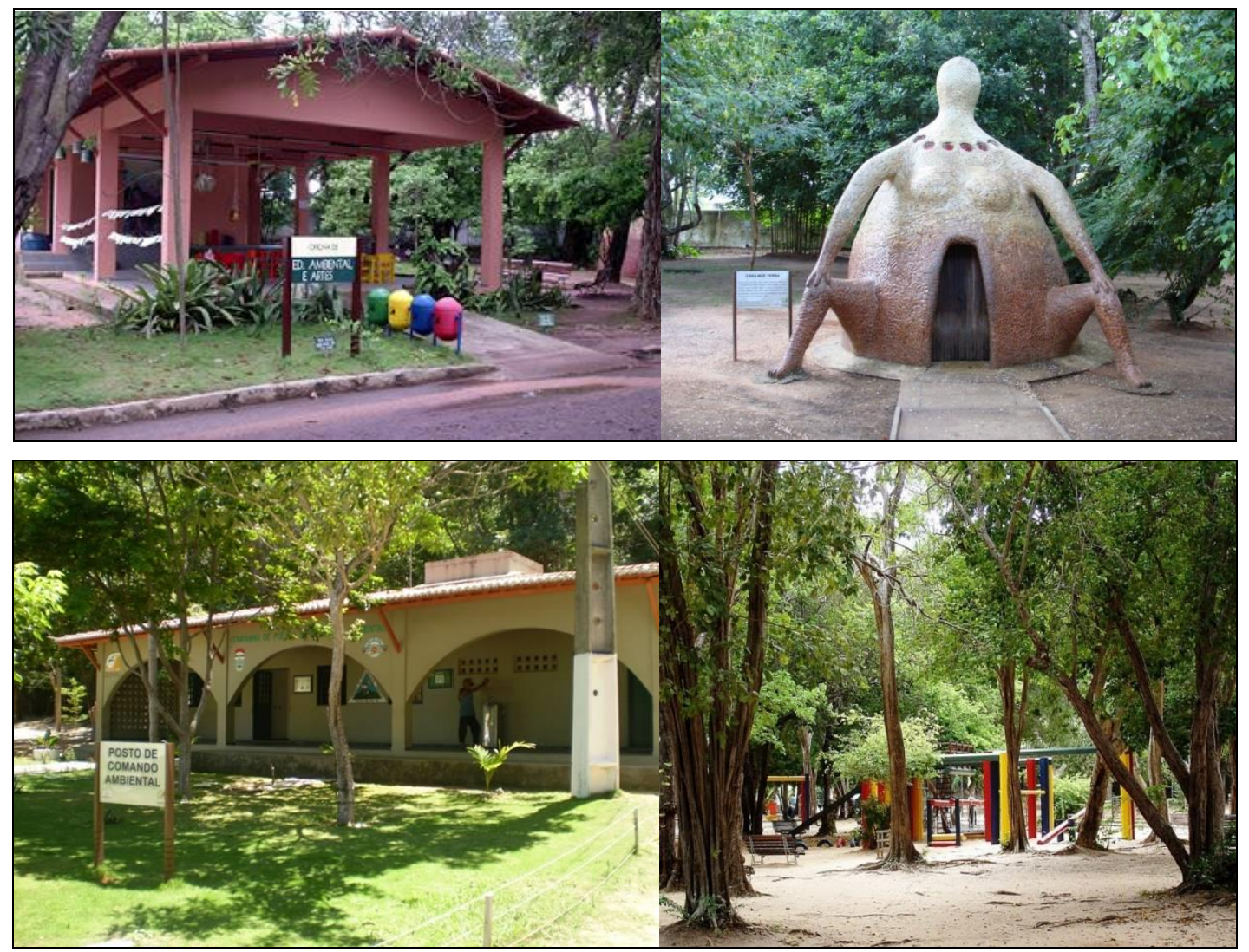

Figura 3: A) Casa da Educação Ambiental; B) Mãe Terra de Mauricio Panella; C) Posto de Comando Ambiental e D) Parque Infantil, Natal/RN. Fonte: IDEMA, 2012.

Figure 3: A)House of Environmental Education; B) Mother Earth of Mauricio Panella; C) Environmental Control Station and D) Playground, Natal / RN. Source: IDEMA, 2012

No centro de visitantes há uma sala de exposição permanente chamada de "Parque das Dunas: um encontro com sua natureza". Onde se localiza amostras do bioma mata atlântica com sua vegetação e animais empalhados, bem como mapas e história do parque; uma das principais partes do parque é onde se localiza o viveiro, onde estão sendo cultivadas mudas de vegetais nativos do parque, utilizadas 
principalmente no reflorestamento e recuperação de áreas de Mata Atlântica. Tem três trilhas interpretativas que seguem em média de $6 \mathrm{~km}$ e meio de caminhada onde os aspectos e elementos do ecossistema dunar podem ser observados.

A interpretação ambiental deve ser entendida como sendo o "ato de decodificar" os conhecimentos disponíveis sobre um determinado objeto ou tema, no sentido de orientar, avisar e sensibilizar os visitantes (SANTOS et al., 2011). Trilhas interpretativas guiadas ou auto-guiadas são recomendadas e utilizadas em interpretação ambiental por oferecerem oportunidades de um contato direto com o ambiente natural, direcionado ao aprendizado e à sensibilização (Santos et. al., 2011). As trilhas, como meio de interpretação ambiental, visam não somente a transmissão de conhecimento, mas também propiciar atividades que revelam os significados e as características do ambiente por meio de usos dos elementos originais, por experiência direta e por meios ilustrativos, sendo assim, encaixa-se como um instrumento básico de Educação Ambiental (SANTOS et al., 2011 p.191).

\section{Ecoturismo e Lazer no Parque}

Os Parques desempenham importante papel para a recreação e lazer em contato com a natureza. No Parque das Dunas observa-se o turismo de lazer ecológico nas trilhas; sendo permitida por ser uma atividade de baixo impacto segundo o Código Florestal, Artigo $3^{\circ}$ Inciso $X$ da linha $C$ da Lei Federal número 12.651/2012; o turismo cultural (eventos e shows). Os agentes do Parque das Dunas têm formação em Educação Ambiental e desempenha importante papel para a comunidade local e para turistas que visitam o parque.

Unidades de conservação de proteção integral possuem a manutenção dos ecossistemas livres de alteração causadas por interferência humana, se admite, em regra, apenas o uso indireto desses recursos naturais com a exceção dos casos previstos na Lei 9.985/2000 (LIMA, 2007). A idealização de Parque como área protegida surgiu com os Parques Norte-Americanos, principalmente quando foi criado o Parque Nacional de Yellowstone em 1872.

Na concepção dos "parques nacionais" norte-americanos, na segunda metade do século XIX, pela qual porções de território consideradas "intocadas" foram transformadas em áreas naturais protegidas, nas quais não poderia haver morador. Essas áreas selvagens foram criadas em benefício das populações urbanas norte americanas que poderiam, como visitantes, apreciar as belezas naturais. Essa representação do mundo natural defendida pelos "preservacionistas puros" justificou a criação de áreas naturais protegidas e intactas (DIEGUES, 2001, p.53).

Essa ideologia conservacionista espalhou-se para o resto do mundo. A noção de mito naturalista, da natureza intocada, do mundo selvagem diz respeito a uma representação simbólica pela qual existiriam áreas naturais intocadas e intocáveis pelo homem, em estado "puro" até anterior ao aparecimento do homem. Esse mito supõe a incompatibilidade entre as ações de quaisquer grupos humanos e a conservação da natureza. $O$ homem seria, desse modo, um destruidor do mundo natural e, portanto, deveria ser mantido separado das áreas naturais que necessitariam de uma "proteção integral". O mito moderno da natureza intocada contempla uma concepção biocêntrica das relações homem/natureza, pela qual o mundo natural tem direitos idênticos ao ser humano. $O$ homem não teria o direito de 
dominar a natureza. Fundamenta-se nas grandes religiões e sobretudo na idealização cristã do paraíso perdido (DIEGUES, 2001, p.53).

Para relativizar as práticas antropocêntricas no domínio da natureza, o ecoturismo representa uma estratégia. Para Ruschmann, (2001), o turismo "brando", ecológico, naturalista, personalizado e realizado em grupos pequenos de pessoas tende a caracterizar os fluxos turísticos do futuro. As atividades seletivas realizadas em equipamentos qualitativamente estruturados, tanto nos serviços prestados como em sua arquitetura e em seu tamanho, constituem o potencial dos movimentos turísticos para o próximo milênio (RUSCHMANN, 2001).

\begin{abstract}
A atividade do ecoturismo deve abranger, em sua conceituação, a dimensão do conhecimento da natureza, a experiência educacional interpretativa, a valorização das culturas tradicionais locais e a promoção do desenvolvimento sustentável (BARROS e LA PENHA, 1994, p.19).
\end{abstract}

O ecoturismo como um segmento da atividade turística, que utiliza de forma sustentável, o patrimônio natural e cultural, incentiva sua conservação e busca a formação de uma consciência ambientalista através da interpretação do ambiente, promovendo o bem-estar das populações envolvidas (BARROS e LA PENHA, 1994).

O crescente envolvimento da sociedade nas questões ambientais, pressionando governo e instituições para o estabelecimento de critérios cada vez mais rígidos quanto ao impacto ambiental na implantação de empreendimentos, aliado a uma crescente busca do homem por uma relação mais íntima e frequente com a natureza, recomenda a não restrição do conceito de ecoturismo, de forma a acompanhar a dinâmica deste segmento. Os componentes da definição podem vir a ser integralmente absorvidos por outros segmentos ou atividades do turismo, que talvez hoje não sejam considerados ecoturísticos, mas cuja evolução deve ser incentivada (BRASIL, 1994, p.19).

Em Áreas de Proteção Ambiental o ecoturismo pode gerar benefícios:

\begin{abstract}
Possibilidades de uma maior integração das UCs (Unidades de Conservação) com comunidades locais e com a sociedade mais ampla; circulação de informação ambiental por meio de programas educativos e da própria visitação; aumento da oferta regional de espaços de recreação e lazer; adesão de visitantes às tarefas de fiscalização; facilidade de controle sobre grupos organizados; divulgação da própria Unidade e o estabelecimento de "redes" de interessados em sua manutenção (SERRANO; BRUHNS, 1997, p.111).
\end{abstract}

O Ecoturismo assim como o Turismo Pedagógico para Educação Ambiental configuram-se sob a ética do Turismo Sustentável. Qualidade de "Turismo que é economicamente viável, mas não destrói os recursos dos quais o turismo no futuro dependera, principalmente o meio ambiente físico e o tecido social da comunidade" (SWARBROOKE, 2000, p.19). O turismo sustentável aproxima-se do ideal apropriados para Áreas de Proteção Ambiental cujos planos de manejo prevê o desenvolvimento de atividades sustentáveis. 
De toda forma, a missão do ecoturismo encarrega-se de levar seus clientes a repensar a vida social, suas relações com os semelhantes, com a cidade em que vivem, com o meio natural, suas ações, sem se apegar a discursos ecológicos simplistas e inflamados (MENDONÇA; NEIMAN, 2003, p.74).

Outro segmento importante para empreender-se no Parque trata-se do Turismo Pedagógico para fins de Educação Ambiental para grupos de escolares em visitas agendadas. O Turismo Pedagógico é o nicho de mercado que mais que dobrou nos últimos cinco anos. Dados do cadastro nacional de prestadores de serviço do setor turístico do Ministério do Turismo, mostram que, atualmente, 2.129 agências de viagem operam no segmento "estudos e intercâmbio", 125\% a mais do que em 2009, quando eram 945. Outro dado importante trata-se do fato de que o Turismo pedagógico tem sido o nicho que duplicou nos últimos anos (BRAGA, 2014).

As empresas que optam pelo ecoturismo têm restrições ao termo educação devido a sua ligação quase que direta ao ambiente escolar, com todas as suas limitações metodológicas (MENDONÇA e NEIMAN, 2003, p.74). Portanto, a educação está no cerne da missão do ecoturismo. Uma experiência transformadora de ensino, fora do ambiente da sala de aula. Essa é a proposta do turismo pedagógico. O segmento viagens para "estudos e intercâmbio" são exemplos de turismo pedagógico. Ao contrário do tradicional passeio escolar, que geralmente visa apenas lazer, o turismo pedagógico se caracteriza por viagens programadas dentro do calendário escolar, além de ser objeto de avaliação (BRAGA, 2014).

O turismo pedagógico transcende a ideia de que o ensino só ocorre na escola e só com o professor. O Turismo pedagógico ainda não se consolidou na cultura brasileira como segmento do turismo, contudo, alinha-se às premissas da ética sustentável e serve para contextualizar o ensino do professor em sala de aula. $O$ passeio torna-se oportunidade de atividade pedagógica de sensibilidade ambiental quando se por meio da experiência, vivência e transformação aos estudantes (BRAGA, 2014).

Educação Ambiental para professores da rede pública e tema do curso ministrado pelo Governo do Estado do Rio Grande do Norte através do IDEMA, do Parque Estadual Dunas de Natal e do Setor de Planejamento em Educação Ambiental - SPEA oferece curso em Educação Ambiental destinado a professores da rede pública de ensino. Com o objetivo de capacitá-los dentro do contexto ambiental, o curso "Da Teoria à Prática" contribui para a compreensão dos princípios da responsabilidade ambiental e de que forma os profissionais em educação podem aplicar os conhecimentos em sala de aula sobre os principais problemas ambientais encontrados na atualidade, além de mostrar os ecossistemas encontrados no Brasil e no estado do Rio Grande do Norte. O conteúdo programático aborda Estratégias de aprendizagem em Educação Ambiental, Sustentabilidade, Oficinas Ecológicas, Espaço não formal na EA e Elaboração de Projetos (Figura 4).

De acordo com levantamento florístico realizado na área do "Parque Estadual Dunas do Natal", verifica-se o reconhecimento de 350 espécies nativas distintas, das quais aproximadamente 200 já identificadas em gênero e espécie, havendo ainda outras a serem coletadas, na dependência de sua eventual floração (PARQUE DAS DUNAS, 2016). 


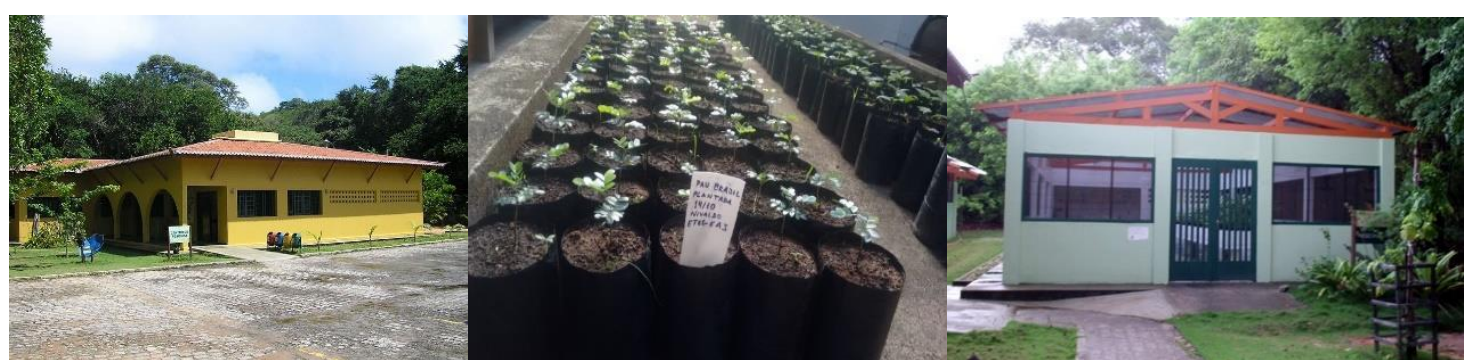

Figura 4: A) Centro de Pesquisa, B) Mudas de Arvores C) Estufa (Viveiro). Natal, RN. 2012. Figure 4: A) Research Center, B) Tree saplings C) Greenhouse. Natal, RN.

Fonte: IDEMA.

Source: IDEMA, 2012.

Parque oferece como serviços aos visitantes, trilhas interpretativas e educativas onde são seis $\mathrm{km}$ e meio de caminhada distribuídos entre as trilhas Ubaia Doce, Peroba e Perobinha, como proposta de sensibilização ambiental durante contato direto com a natureza; a trilha Ubaia Doce é a mais longa, demorando em torno de duas horas e meia para ser concluída; a Peroba é a mais utilizada pelos visitantes, tendo sua conclusão em torno de uma hora e meia. A trilha Perobinha dura em torno de trinta minutos e é a mais utilizada pelas crianças de passeios escolares; toda subida a uma trilha é acompanhado por um policial militar da polícia ambiental; são realizadas em dias ensolarados (Figura 5). Assim, a área de Uso Público do Bosque dos Namorados destaca-se pela exuberante arborização e energia revigorante.

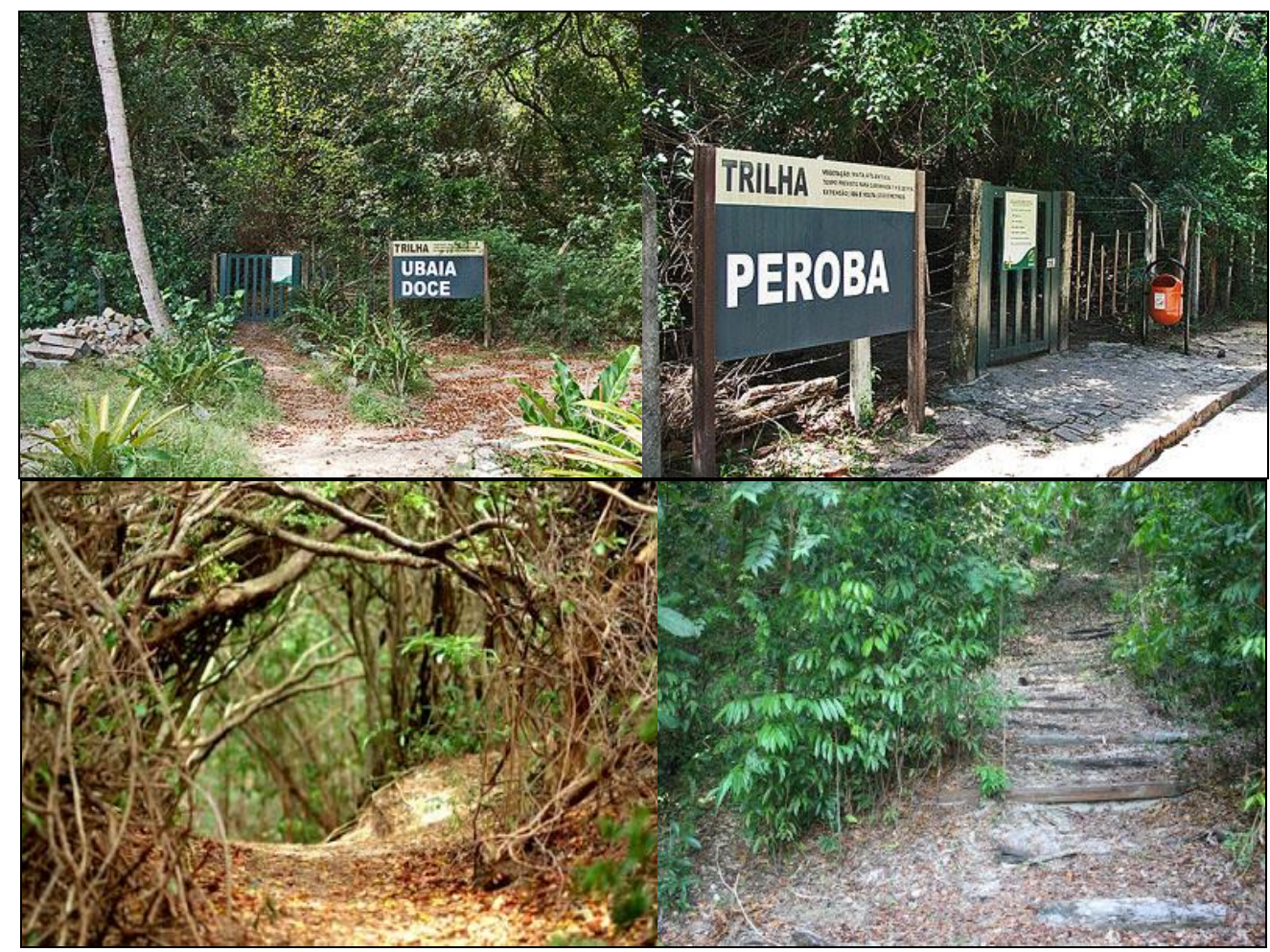

Figura 5: Imagens das Trilhas do Parque das Dunas, Natal/RN. Fonte: IDEMA, 2012. Figure 5: Images of the Trails in the Dunas Park, Natal/RN. Source: IDEMA, 2012. 


\section{Turismo no Parque}

O turismo de parque é bastante seletivo, não configurando um turismo de massa dada a sua característica de elementos naturais que precisam ser preservados cuidadosamente, não comportando grande capacidade de carga, referindo-se à quantidade máxima diária que o local pode receber, sem que seja afetada de forma negativa; mas sendo muito significativo para a localidade e para quem visita (TEIXEIRA; VENTICINQUE, 2014).

Em relação ao numero de visitantes, há registros na mídia de uma frequência de quase 5 mil visitantes por final de semana no ano de 2015. No entanto, estima-se em $2 \%$, a participação de turistas visitando o parque (PARQUE DAS DUNAS, 2016). De acordo ao estudo Quanto Vale o Verde, somente um número reduzido de UCs brasileiras que controlam o fluxo de visitantes. Apenas $20 \%$ possuem registro, totalizando 16,8 milhões de visitantes anuais. Caso todas as UCs realizassem o controle de visitantes teríamos um resultado mais preciso e uma mensuração do impacto econômico ainda maior (YOUNG; MEDEIROS, 2018).

Alguns dados do parque podem demonstrar sua dinâmica e importância para a cidade e no cenário turístico local. Vale ressaltar que a atividade turística no parque não é representativa, economicamente falando, o que não desmerece em nada o seu valor, uma vez que é essencial a cultura de natureza, meio ambiente, ecologia, a qual, mesmo contemplativa é bastante relevante em termos de realidade presente, bem como de futuro de um ambiente que precisa ser cada vez mais conservado e preservado (DINIZ, 2010).

As 20 Metas de Aichi 2011-2020, objetivam pontos estratégicos fazendo referência à preservação e conservação da biodiversidade, formando a base do planejamento relacionado à implementação da Convenção sobre Diversidade Biológica. A Meta 11 de Aichi esclarece que até o ano de 2020 sejam instituídas Áreas de Conservação de pelo menos $17 \%$ das áreas terrestres e continentais e $10 \%$ das zonas costeiras e marinhas devem estar conservadas, com gestão efetiva e equitativa, em aspecto quantitativo e qualitativo, sendo satisfatoriamente interligadas por corredores ecológicos, ecologicamente conservadas, e com sistemas bem conectados de áreas protegidas; o Parque das Dunas, por sua vez, acaba sendo de fundamental importância para o cumprimento deste acordo, visto o seu tamanho em termos geográficos e sua importância para o país e para o mundo (CONVENTION ON BIOLOGICAL DIVERSITY,2016)

O recente acordo de Paris em (2015) assinado por 195 países é o grande direcionador das políticas e ações para as próximas décadas. O acordo estabeleceu medidas para deter o aumento da temperatura global (BRASIL, 2016).

A Cop22 em Marrocos agora em novembro de (2016) funciona como evento de consolidação do acordo global do meio ambiente e, implementa o acordo de Paris (2015), (MARRAKESH, 2016).

Aproximação de turismo e meio ambiente incluídos em parques urbanos, torna-se a alternativa mais sensata, troca equilibrada de interesses do turista que quer ver, sentir, estar presente, contemplar, interagir com o meio natural do parque, seu conjunto de recursos de fauna e flora que exigem cuidados, respeito, não interferência, observação/contemplação. O comportamento esperado para o parque pode garantir a experiência e vivência adequada ao turismo no parque.

O turismo de parque viabiliza a Educação Ambiental e o lazer no parque pode 
ser um indutor de preservação do meio ambiente (Quadro 1). O turismo em parques urbanos configura-se numa estratégia de Educação Ambiental para melhorar imagem do destino Natal e atrair o público que busca o turismo responsável e atento ao meio ambiente.

Quadro 1: Comportamento esperado em Turismo Pedagógico em Parques Urbanos.

Table 1: Expected behavior in Pedagogical Tourism in Urban Parks, Natal, RN.

\begin{tabular}{|c|c|}
\hline Interesses do Turista & O que o Parque requer \\
\hline Ansiedade/Pressa/ser percebido & Cuidado/Silêncio/Perceber \\
\hline Alternativas/Escolhas & Preservação/Conservação \\
\hline Consumir & Respirar/Essência/Equilíbrio \\
\hline Facilidades/vantagens/Competições & Gestão Eficiente/Ética \\
\hline Contato/Toque & Não-interferência \\
\hline Aproximação & Respeito \\
\hline Experiência & Observação/Contemplação \\
\hline Sonho/Fantasia & Despertar/Revelar \\
\hline Extrair souvenires & Fotografar/Assegurar para o Futuro/Manter \\
\hline
\end{tabular}

Fonte: Dados do Estudo, 2016.

Source: Dados do Estudo, 2016.

\section{Considerações Finais}

Os parques urbanos contribuem para o bem-estar e a qualidade de vida e constitui espaço propício ao turismo pedagógico durante o lazer. $\mathrm{O}$ turismo pedagógico pode ser oportunidade para instrumentalizar a Educação Ambiental de modo a contextualizar o ensino teórico da sala de aula de forma interativa com a natureza. Demonstrar o papel dos ecossistemas e fornecer diretrizes para o planejamento do turismo sustentável.

A melhoria da gestão do Parque das Dunas como atrativo turístico demanda planejamento contínuo com plano de ação, alocação de recursos centralizados no Global Environmental Facility - GEF, recursos da compensação ambiental e do FUNBIO. Para isso, o IDEMA precisa enviar planos e projetos para angariar fundos destinados a esses recursos, contemplando responsabilidades, decisão, coordenação, controle, entre outros. Busca de parcerias com empresas participantes dos Polo Turísticos, promoção de uma campanha de divulgação e inclusão nos roteiros turísticos convencionais.

O parque representa uma opção decisiva para o turismo ecológico, de lazer e para o turismo pedagógico, principalmente, para educadores e grupos escolares. Configura-se no espaço ideal para promover um turismo de responsabilidade ecológica no contexto urbano.

\section{Referências}

BARBOSA, M.A.C.; ZAMBONI, R.A. Formação de um 'Cluster' em Torno do Turismo de Natureza Sustentável em Bonito - MS. Brasília, 2000.

BARROS, S.M.; LA PENHA, D. Diretrizes para uma política nacional de ecoturismo. Brasília: Embratur, 1994.

BARDIN, L. Análise de conteúdo. Lisboa: Edições 70, 1977. 
BECKER, B. Políticas e planejamento do turismo no Brasil. Caderno Virtual de Turismo, vol. 1, núm. 1, 2006.

BELTRÃO, O. Turismo a Indústria do Século XXI. São Paulo: Novo Século, 2001. BRAGA, G.H. Turismo pedagógico cresce no Brasil. Brasília: Ministério do Turismo, 2014.

BRASIL. Sistema Nacional de Unidades de Conservação da Natureza: Lei no 9.985, de 18 de julho de 2000. Disponível em:<http://www.planalto.gov.br/ ccivil 03/leis/L9985.htm>. Acesso em: 10 de setembro de 2016.

CARVALHO, M.M. Clima urbano e vegetação: estudo analítico e prospectivo do Parque das Dunas em Natal (Dissertação de Mestrado), Natal: UFRN, 2001.

CARVALHO, I.C.M. Educação Ambiental: a formação do sujeito ecológico. $2^{\circ}$ ed. São Paulo: Cortez, 2006.

CONVENTION ON BIOLOGICAL DIVERSITY. Aichi Biodiversity Targets. Disponível em:<https://www.cbd.int/sp/targets/>. Acesso em: 15 de dezembro de 2016.

DIEGUES, A.C.S. O mito moderno da natureza intocada. São Paulo: Hucitec, 2001.

DINIZ, R.F. Cuidado ambiental em tempos de sustentabilidade: explorando dimensões da conduta sustentável com estudantes universitários. Natal, 2010.

GEF - O Global Environmental Facility - em português Fundo Global para o Meio Ambiente. Disponível em:<http://www.funbio.org.br/o-que-fazemos/agencia-gef/>. Acesso em: 15 de dezembro de 2016.

IDEMA. Unidades de conservação: Parque estadual Dunas do Natal. Disponível em:<http://www.idema.rn.gov.br/Conteudo.asp?TRAN=ITEM\&TARG=941\&ACT=\&P $A G E=0 \& P A R M=\& L B L=$ Unidades $+d e+$ Conserva\%E7\%E3o $>$.Acesso em: 01 de setembro de 2016.

LIMA, S.B.S. A influência norte-americana nos sistemas de áreas verdes do urbanista Francisco Prestes Maia. Revista eletrônica da área Paisagem e Ambiente, FAU.USP, n. 05, dezembro 2007.

MANETTA, B.A.R. et. al. Unidades de Conservação. Belo Horizonte: Engenharias On-line, 2001.

MARRAKESH. COP22. Disponível em:<http://cop22.ma/en/\#gotocop>. Acesso em: 14 de novembro de 2016.

MENDONÇA, R.; NEIMAN, Z. À sombra das árvores: transdisciplinaridade e Educação Ambiental em atividades extraclasse. São Paulo: Chronos, 2003.

MYERS, N.; MITTERMEIER, R.A.; MITTERMEIER, C.G.; FONSECA, G.A.B.; KENT, J. Biodiversity hotspots for conservation priorities. Nature, v. 403, n. 6772, p. 853, 2000.

MINISTÉRIO DO MEIO AMBIENTE. Resolução CONAMA nㅜ 306, de 5 de julho de 2002. Publicada no DOU no 138, de 19 de julho de 2002, Seção 1, páginas 75-76.

MINISTÉRIO DO MEIO AMBIENTE. Lei Federal no 11.428, de 22 de dezembro de 2006 - Lei da Mata Atlântica. Disponível em:<http://www.mma.gov.br>. Acesso em: 09 de dezembro de 2016. 
MINISTÉRIO DO TURISMO. Agenda Estratégica 2013-2022. Brasília: Conselho Nacional de Turismo, 2012.

OMT. Definição de Turismo. Disponível em: <http://www.dadosefatos.turismo. gov.br/>. Acesso em: 15 de setembro de 2016.

O Plano Diretor da Cidade do Natal. Lei Complementar № 082, De 21 de Junho de 2007.

PARQUE DAS DUNAS. O Parque: Apresentação 2016. Disponível em: $<$ http://parquedasdunas.rn.gov.br/>. Acesso em: 01 de setembro de 2016.

PLANALTO, L. E. I. 6.938, DE 31 DE AGOSTO DE 1981. Dispõe sobre a Política Nacional do Meio Ambiente, seus fins e mecanismos de formulação e aplicação, e dá outras providências. Disponível em: <www.planalto.gov.br>. Acesso em 13 de dezembro de 2016.

RUSCHMANN, D. Turismo e Planejamento Sustentável: A Proteção do meio Ambiente. 8. ed. São Paulo: PAPIRUS, 2001.

SANTOS, M.C.; FLORES, M.D.; ZANIN, E.M. Trilhas interpretativas como instrumento de interpretação, sensibilização e Educação Ambiental na APAE de Erechim/RS. Vivências. Vol.7, N.13: p.189-97, 2011.

SERRANO, C.M.T.; BRUNHS, H. A vida e os parques: proteção ambiental, turismo e conflitos de legitimidade em unidades de conservação. Viagens à natureza. Viagens à natureza: turismo, cultura e ambiente, Campinas: Papirus, 1997.

SEARH/COTIC. Unidade de Conservação. Decreto Estadual no 7237 de 1977.

SECOM/IDEMA. Lei n.- 4.286, de 06 de dezembro de 1973, (alterada pela Lei n.은 4.414, de 04 de novembro de 1974), e a Coordenadoria de Meio Ambiente (CMA), criada por meio do Decreto n. -8.718 de 16 de setembro de 1983. 31 de janeiro de

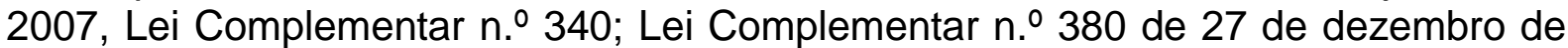
2008.

SILVA, J.A. Direito Ambiental Constitucional. 2º edição, São Paulo: Malheiros Editores, 1998.

SILVA, O.V.; SANTOS, S.G. Turismo E Meio Ambiente: A Preservação De Patrimônios Naturais Por Meio Do Ecoturismo. Garça: FAEF, 2010.

SNUC. Sistema Nacional de Unidades de Conservação da Natureza. Lei №. 9.985, de 18 de julho de 2000. Decreto №. 4.340, de 22 de agosto de 2002. 2. Ed. Aumentada. Brasília: MMA/SBF e Lei no6.938, de 31 de agosto de 1981.

SWARBROOKE, J. Turismo Sustentável. Conceitos e Impacto Ambiental. São Paulo: Aleph, 2000.

TEIXEIRA, M.G.; VENTICINQUE, E.M. Fortalezas e fragilidades do Sistema de Unidades de Conservação Potiguar. Desenvolvimento e Meio Ambiente, v. 29, 2014.

YOUNG, C.E.F.; MEDEIROS, R. Quanto vale o verde: a importância econômica das unidades de conservação brasileiras. Rio de Janeiro: Conservação Internacional, 2018. 
Aretha Julianna Moura-dos-Santos: Universidade Federal do Rio Grande do Norte, Natal, RN, Brasil

E-mail: aretha.infinity@gmail.com

Link para o currículo Lattes: http://lattes.cnpq.br/6091568295351657

Mauro Lemuel Oliveira-Alexandre: Universidade Federal do Rio Grande do Norte, Natal, RN, Brasil

E-mail:mauro_alx@yahoo.com.br

Link para o currículo Lattes: http://lattes.cnpq.br/7233203993967359

Ana Beatriz Gomes-Ferreira: Universidade Federal do Rio Grande do Norte, Natal, RN, Brasil

E-mail: beatriz_biologia@hotmail.com

Link para o currículo Lattes: http://lattes.cnpq.br/3428643449624579

Juliana Garcia Vidal-Rodrigues: Faculdade Campo Real, Guarapuava, PR, Brasil

E-mail: julianagarciavr@gmail.com

Link para o currículo Lattes: http://lattes.cnpq.br/6404895681799794

Sueli Aparecida Moreira: Universidade Federal do Rio Grande do Norte, Natal, RN, Brasil

E-mail: suelimoreira@yahoo.com.br

Link para o currículo Lattes: http://lattes.cnpq.br/9469781068838287

Data de submissão: 21 de outubro de 2018

Data de recebimento de correções: 15 de dezembro de 2018

Data do aceite: 15 de dezembro de 2018

Avaliado anonimamente 